Diabetologia, Suppl. to 9, 331-338 (1973)

(C) by Springer-Verlag 1973

\title{
Pharmacokinetics of Glipizide in Man: Influence of Renal Insufficiency
}

\author{
L. Balant, G. Zahnd, A. Gorgia, R. Schwarz and J. Fabre \\ Départment de Médecine, Université de Genève, Switzerland
}

Received: April 10,1973, and in revised form: June 26, 1973, accepted: June 27, 1973

\begin{abstract}
Summary. Four subjects received $5 \mathrm{mg}{ }^{14} \mathrm{C}$-glipizide orally and 3 subjects $1 \mathrm{mg}$ intravenously. The average absorption of the oral dose was nearly $100 \%$ with peak plasma levels occurring between 90 and $360 \mathrm{~min}$. The apparent half-life of plasma radioactivity was approximatively $3.7 \mathrm{~h}$, the disappearance of radioactivity following complex kinetics due to metabolism of the drug. Extraction with $\mathrm{CH}_{2} \mathrm{Cl}_{2}$ and chromatography showed that in plasma $85 \%$ of the total radioactivity corresponded to unchanged glipizide, but in urine $98 \%$ to more polar and more readily excreted metabolites. The urinary excretion is $68 \%$ of the dose. The hypoglycaemic effect of glipizide
\end{abstract}

is comparable to glibenclamide. The administration of ${ }^{14} \mathrm{C}$-glipizide to two patients with renal insufficiency showed that the metabolism of the drug is independent of kidney function, that the rate of disappearance of the unchanged glipizide was approximately the same as in normals, but that the "halflife" of the metabolites was increased to $20 \mathrm{~h}$ and more.

Key words: Diabetes mellitus, sulphonylurea, glipizide, pharmacokinetics, metabolism, excretion, renal insufficiency.
Glipizide is a sulfonylcyclohexylurea derivative with a hypoglycaemic effect about 100 times that of tolbutamide. Furthermore, the safety margin between efficacy and toxicity was 200 times greater in experimental animals, compared with tolbutamide [1]. This compound was well tolerated in patients and suitable for use in the treatment of maturity-onset diabetes in daily doses ranging from 2.5 to $15 \mathrm{mg}$ [2]. Ambrogi $e t$ al. reported data on the behaviour of the drug given to two normal subjects. The plasma half-life was approximately $2 \mathrm{~h}$. Most of the compound was excreted in the urine, mainly in the form of metabolites; almost $100 \%$ of the dose was excreted by the fourth day [3].

Since glipizide is likely to be used clinically, we extended this study to 9 other subjects. A more thorough investigation was made into the pharmacokinetics of this sulphonylurea. We studied the fate of its various metabolites in the plasma and urine as well as the characteristics of insulin response after its oral and intravenous administration.

In view of the predominantly urinary excretion of the drug, we believed it important to examine the effect of renal insufficiency on its pharmacokinetics, since sulphonylureas are often prescribed to diabetics with kidney disturbances. It is well known that renal failure delays the excretion of tolbutamide $[4,5]$, acetohexamide [6] and chlorpropamide [7]. However, for the more potent second generation sulphonylureas there are pertinent data only of two patients with impaired renal function who were given $50 \mathrm{mg}$ glibornuride [8]. Information is lacking in this respect about glibenclamide and glipizide. The observations made in this additional part of our study proved to be useful in understanding the pharmacokineties of glipizide in normal subjects.

\section{Methods \\ Experimental Protocol}

The subjects in the control group were adult men and women hospitalized for various disorders, but showing no liver or kidney insufficiency and no abnormality of their carbohydrate metabolism. Two patients had impaired renal function with a glomerular filtration rate (GFR) of $30 \mathrm{ml} / \mathrm{min}$ (patient G.B.) and $10 \mathrm{ml} / \mathrm{min}$ (E. G.). The diet consisted of regular hospital food. Tests were begun at $7.30 \mathrm{am}$, after $12 \mathrm{~h}$ fasting.

Intravenous administration. Each subject received $1 \mathrm{mg}$ glipizide (Fig. 1) labelled with ${ }^{14} \mathrm{C}$ (specific activity

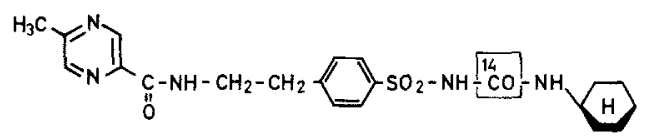

Fig. 1. Glipizide $\mathrm{N}-\{4-[\beta$-(5-methyl-pyrazine-2-carboxamido)-ethyl]-benzene-sulfonyl $\}-N^{\prime}$-cyclohexyl-urea

$23 \mu \mathrm{Ci} / \mathrm{mg}$ ). The patients were fasted and kept in bed until noon, when they received a normal meal. They were carefully observed throughout the experimental period and were given no other drug which might interfere with the study. Blood was collected in heparinized tubes between 0 and $48 \mathrm{~h}$ at the times indicated in Fig. 2. All urine and faeces up to 3 days were kept for examination. The collection intervals for urine were $0-3 \mathrm{~h}, 3-6 \mathrm{~h}, 6-12 \mathrm{~h}, 12-24 \mathrm{~h}, 24-48 \mathrm{~h}, 48-72 \mathrm{~h}$.

Oral administration. Each subject received one tablet containing $5 \mathrm{mg}{ }^{14} \mathrm{C}$-glipizide (specific activity $69 \mu \mathrm{Ci} / \mathrm{mg}$ ), $15 \mathrm{mg}$ microcrystalline cellulose, $15 \mathrm{mg}$ starch, $3 \mathrm{mg}$ stearic acid and $162 \mathrm{mg}$ lactose. Three hours after the administration of the drug, $1 \mathrm{mg}$ 
glucagon was injected intravenously in order to prevent hypoglycaemia. This protective measure seemed indicated since renal insufficiency constitutes an important predisposition to hypoglycaemia in diabetics treated with sulphonylureas [7]. Blood samples were collected between 0 and $48 \mathrm{~h}$ at the times indicated in Fig. 4 . Collection of urine and faeces was done as in the protocol for intravenous administration, but was uncontinued for 4 days.

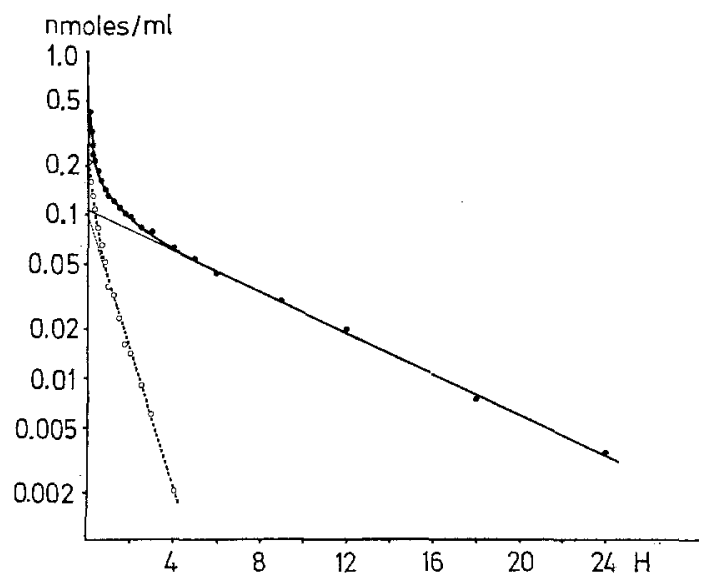

Fig. 2. Plasma concentrations of total radioactivity (expressed as nmoles per $\mathrm{ml}$ ) in one normal subject following intravenous administration of $1 \mathrm{mg}{ }^{14} \mathrm{C}$-glipizide $(0-0)$. Tentative graphical analysis of the results according to the two compartment open model $(\mathrm{O} \ldots \mathrm{O})$

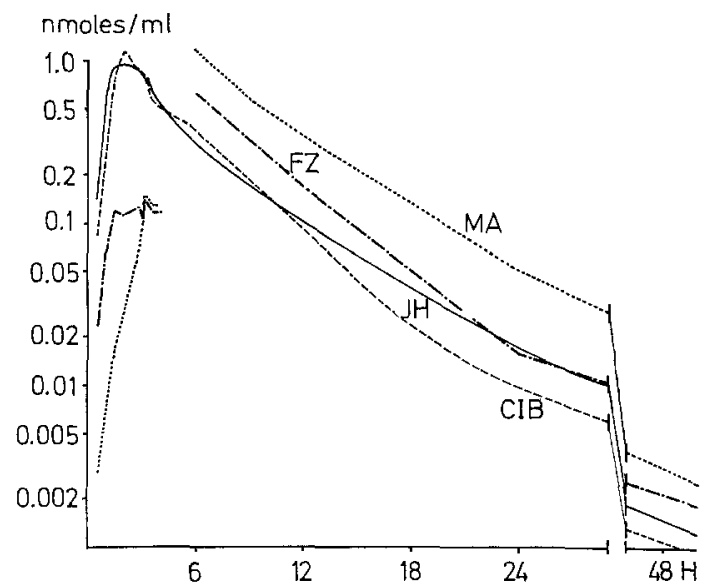

Fig. 3. Plasma concentrations of total radioactivity (expressed as nmoles per $\mathrm{ml}$ ) in 4 control subjects following oral administration of a tablet, containing $5 \mathrm{mg}$ of ${ }^{14} \mathrm{C}$-glipizide

\section{Measurements in Plasma}

Total radioactivity, glucose and insulin were measured in all samples. Growth hormone and the distribution of radioactivity between unchanged glipizide and its metabolites were determined only in selected samples (extraction and TLC chromatography).
Total radioactivity was measured by counting 0.2 and $0.5 \mathrm{ml}$ plasma in $10 \mathrm{ml}$ Instagel (Packard), using a liquid scintillation counter TRI CARB 3000 (Packard). Correction for quenching was made by a combination of internal $\left({ }^{14} \mathrm{C}\right.$-toluene) and external (channel ratio) standardisation.

Glucose was determined by a modification of the o-toluidine method without deproteinisation of the samples [9].

Immunoreactive insulin was assayed by a modification of the double antibody method of Hales and Randle [10] and growth hormone according the solidphase technique of Catt [11].

Glipizide metabolites were determined by a combination of extraction and chromatographic methods [3]. The $\mathrm{pH}$ of the plasma samples was adjusted to 4.3 with acetate buffer; the solution was extracted 4 times with 5 volumes methylene chloride; the organic phase was separated by centrifugation; the solvent was evaporated to dryness in a Rotavapor-El (Buchi). The residue was taken up in methanol and the volume of this solution was reduced under nitrogen prior to chromatography. The radioactivity of the aqueous phase was measured. It represents the unextractable metabolites of glipizide.

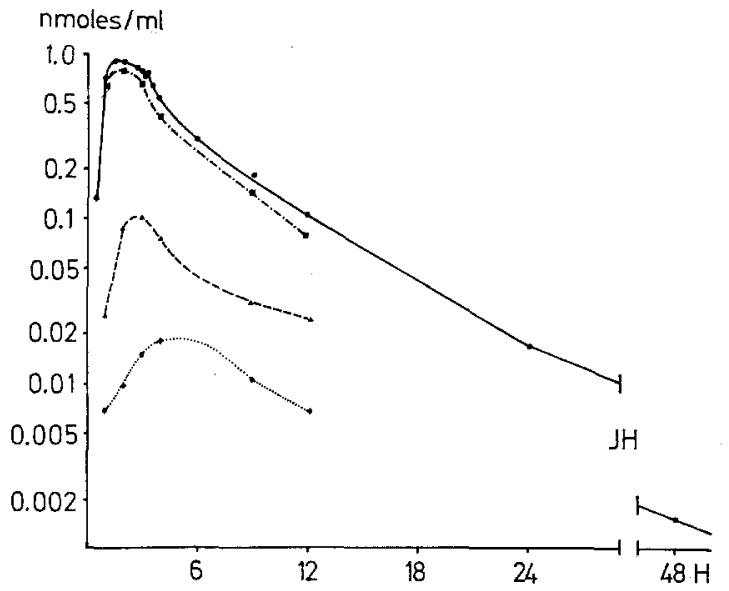

Fig. 4. Plasma concentrations of glipizide and its metabolites (expressed in nmoles per ml) in 1 control subject following oral administration of a tablet, containing $5 \mathrm{mg}$ of ${ }^{14} \mathrm{C}$-glipizide. Total radioactivity (-), extractable glipizide (-.-.-), extractable metabolites (...-), unextractable metabolites $(. \ldots$.

\section{Measurements in Urine}

Total radioactivity was measured in 0.5 and $1.0 \mathrm{ml}$ samples. Correction for quenching was made by internal standardisation of all the samples.

Prior to extraction the urine was concentrated, if necessary, by adsorption on a column of XAD 2 resin and elution with methanol. The eluate was evaporated to dryness under reduced pressure. The residue was taken up in acetate buffer and extracted as described for plasma. 
The unextractable radioactivity was measured in all samples using non-concentrated urine.

\section{Measurements in Faeces}

Total radioactivity was determined on homogenized and lyophilized samples which were combusted in a Sample Oxidizer (Packard).

Prior to chromatography the lyophilized sample was Soxhlet extracted. The resulting ethanol solution was evaporated. The residue was reconstituted in acetate buffer and finally extracted with methylene chloride. The results obtained with thin layer chromatography were not conclusive due to the low-levels of radioactivity and to the presence of natural materials which interfered with the chromatographic migration.

\section{Thin-Layer Chromatography}

Silica gel (Merck HF 254) was spread $300 \mu$ in thickness using Desaga's manual apparatus. The plates were air dried and activated 15 min at $120^{\circ} \mathrm{C}$ before application of the plasma or urine extracts.

Six solvent systems have been used, but systems $\mathrm{C}$ [3] and $\mathrm{H}$ [12] were found to be most satisfactory. The constituents for system $\mathrm{C}$ were a mixture of benzene, glacial acetic acid, ethyl acetate and acetone $(65: 6: 12: 30)$ and for system $H$, benzene, glacial acetic acid, methanol and acetone $(80: 5: 20: 5)$.

We found that the Rf's of glipizide and its main metabolites [3] were slightly different from the values determined by Valzelli [13].

The radioactivity of the different fractions was measured by scraping $5 \mathrm{~mm}$ wide bands and counting the silica gel in $10 \mathrm{ml}$ Bray's medium [14]. This method has been found to give more precise results than scanning of the plates, but to consume more time.

\section{Paper Chromatography}

Chromatography of urine or plasma extracts was also performed on Whatman No. 1 paper with the basic solvent system $B$ [15] (butylacetate: isopropanol: $\mathrm{H}_{2} \mathrm{O}$ : $\mathrm{NH}_{3}$ in the proportions of $30: 50: 15: 5$ ). The radioactivity of the peaks was measured by eutting $5 \mathrm{~mm}$ wide bands and counting in Bray's medium.

\section{Handling of the Results}

The separation methods described above allow the distinction in plasma and urine of three types of constituents of the total radioactivity: 1 . non-metabolized glipizide, 2. metabolites extractable in methylene chloride, and 3. unextractable metabolites.

All the mathematical conversions (cpm - nmoles/ mI) were performed using a Wang 360 computer.

The pharmacokinetic parameters were tentatively derived by graphical procedures.

\section{Results}

\section{Subjects with Normal Kidney Functions}

Plasma Levels of Glipizide and Its Metabolites

1. After intravenous administration to 3 subjects the total radioactivity decreases according to complex kinetics which cannot be analysed graphically or by the usual computer programs, as can be seen in Fig. 2. The mean apparent "half-life" of the total radioactivity in plasma, as calculated from the linear postdistribution phase, is $3.65 \mathrm{~h}$ for the three subjects.

The apparent volume of distribution was found to be $20.4 \mathrm{l}$. This value is almost certainly an overestimate.

The total radioactivity was not separated into unchanged and metabolized glipizide since the administered dose was too low.

2. After oral administration in 4 subjects with normal kidney functions two situations have been encountered; two subjects had a rapid and two subjects had a delayed gastrointestinal absorption (Fig. 3). In two subjects (J.H. and Cl.B.) the maximum plasma levels were measured at 90 and $120 \mathrm{~min}$ and in two subjects (F.Z. and M.A.) peak levels were reached between 240 and $360 \mathrm{~min}$ after a slow rise of the plasma radioactivity during the first hours of the test.

The maximum plasma concentrations were between 0.85 and $1.25 \mathrm{nmoles} / \mathrm{ml}$.

The decrease of the total radioactivity in plasma follows a complex kinetic pattern such that the elimination of the drug cannot be expressed in terms of a single half-life. The mean value for the $50 \%$ decrease in radioactivity between 6 and $12 \mathrm{~h}$ was found, on average, to be $3.7 \mathrm{~h}$ for the 4 subjects.

Chromatographic examination of the plasma showed that the radioactivity was comprised partly of glipizide, partly of extractable derivatives (most probably hydroxylated glipizide, according to the chromatographic migration), and partly of unextractable metabolites (glucuronides, etc.). The proportion in plasma of unchanged glipizide is about 85 to $80 \%$ of the total radioactivity, with a slight decrease of this value with time (Fig. 4).

\section{Urinary Excretion}

Table 1 shows the excretion of glipizide (occurring almost exclusively in the form of its metabolites) in the urine of 6 subjects with normal kidney functions. Most of the radioactivity was excreted during the first $24 \mathrm{~h}$. In fact after oral administration this quantity amounted to $95.5 \%$ of the total urinary excretion. The route of administration had no influence on the amount excreted in the urine since at $48 \mathrm{~h}$, an average of $68.3 \%$ and $67.9 \%$ of the administered dose was found in the urine of the oral and the intravenous groups respectively.

The graphical representation of the radioactivity excreted per $24 \mathrm{~h}$ periods shows that 5 subjects with 
Table 1. Excretion of the total radioactivity, indicated in \% of the dose, in the urine of 8 subjects following one oral (*) or one intravenous $(+)$ administration of glipizide

\begin{tabular}{|c|c|c|c|c|c|c|c|}
\hline Subjects & $\begin{array}{l}\text { Time of } \\
\text { urine } \\
\text { collection }\end{array}$ & $0-6 h$ & $6-12 \mathrm{~h}$ & $12-24 \mathrm{~h}$ & $24-48 h$ & $48-72 \mathrm{~h}$ & $72-96 \mathrm{~h}$ \\
\hline J.H. & * control & 17.3 & $\begin{array}{l}34.1 \\
51.4\end{array}$ & $\begin{array}{r}8.3 \\
59.7\end{array}$ & $\begin{array}{r}1.7 \\
61.4\end{array}$ & $\begin{array}{r}0.2 \\
61.6\end{array}$ & $\begin{array}{l}0.02 \\
61.6\end{array}$ \\
\hline Cl.B. & * control & 45.5 & $\begin{array}{l}18.3 \\
64.8\end{array}$ & $\begin{array}{r}3.7 \\
68.5\end{array}$ & $\begin{array}{r}1.2 \\
69.7\end{array}$ & $\begin{array}{c}0.08 \\
69.8\end{array}$ & $\begin{array}{l}0.01 \\
69.8\end{array}$ \\
\hline F.Z. & * control & 18.2 & $\begin{array}{l}40.6 \\
58.8\end{array}$ & $\begin{array}{l}12.2 \\
71.0\end{array}$ & $\begin{array}{r}1.4 \\
72.4\end{array}$ & $\begin{array}{r}0.1 \\
72.5\end{array}$ & $\begin{array}{l}0.03 \\
72.5\end{array}$ \\
\hline M.A. & * control & 20.1 & $\begin{array}{l}27.9 \\
48.0\end{array}$ & $\begin{array}{l}16.0 \\
64.0\end{array}$ & $\begin{array}{r}6.0 \\
70.0\end{array}$ & $\begin{array}{r}1.3 \\
71.3\end{array}$ & $\begin{array}{r}0.4 \\
71.7\end{array}$ \\
\hline A.B. & * control & 35.4 & $\begin{array}{l}17.6 \\
53.0\end{array}$ & $\begin{array}{r}6.2 \\
59.2\end{array}$ & $\begin{array}{r}2.1 \\
61.3\end{array}$ & & \\
\hline J.P. & * control & 65.3 & $\begin{array}{r}7.2 \\
72.5\end{array}$ & $\begin{array}{r}1.8 \\
74.3\end{array}$ & $\begin{array}{r}0.2 \\
74.5\end{array}$ & & \\
\hline \multirow[t]{2}{*}{ G.B. } & $\begin{array}{l}\text { * renal } \\
\text { insuffi- } \\
\text { ciency }\end{array}$ & 12.8 & $\begin{array}{l}25.6 \\
38.4\end{array}$ & $\begin{array}{l}13.3 \\
51.7\end{array}$ & $\begin{array}{l}10.8 \\
62.5\end{array}$ & $\begin{array}{r}1.6 \\
64.1\end{array}$ & $\begin{array}{r}0.5 \\
64.6\end{array}$ \\
\hline & & 2.7 & 5.2 & 8.3 & 8.0 & 3.2 & 1.8 \\
\hline E.G. & $\begin{array}{l}\text { * renal } \\
\text { insuffi- } \\
\text { ciency }\end{array}$ & & 7.9 & 16.2 & 24.2 & 27.4 & 29.2 \\
\hline
\end{tabular}

The upper figure in each field represents the excretion per collection interval and the lower figure the cumulative urinary excretion.

Subject E.B. (1 mg intravenously) received only an undetermined part of the dose and was thus not considered in the recovery calculations.

Table 2. Plasma glucose and immunoreactive insulin (IRI) levels of two normal subjects (J.H. and Cl.B.) and two patients with renal insufficiency (G.B. and E.G.) after oral administration of $5 \mathrm{mg}$ glipizide

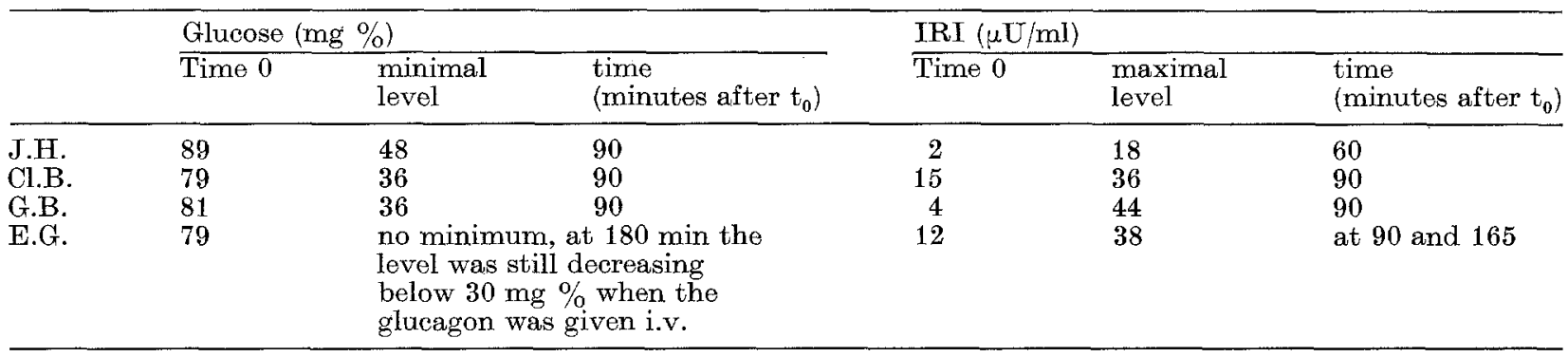

Table 3. Plasma levels of glipizzde and its metabolites 12 h after oral administration

\begin{tabular}{|c|c|c|c|c|c|c|}
\hline & \multicolumn{3}{|c|}{ Concentration in plasma $\left(10^{3} \times\right.$ nmoles $\left./ \mathrm{ml}\right)$} & \multicolumn{3}{|c|}{$\%$ of total radioactivity } \\
\hline & $\begin{array}{l}4 \text { control subjects } \\
\mathrm{GFR}>100 \mathrm{ml} / \mathrm{min}\end{array}$ & $\begin{array}{l}\text { G.B. } \\
30 \mathrm{ml} / \mathrm{min}\end{array}$ & $\begin{array}{l}\text { E.G. } \\
10 \mathrm{ml} / \mathrm{min}\end{array}$ & 4 controls & G.B. & E.G. \\
\hline Total radioactivity & 180 & 260 & 350 & 100 & 100 & 100 \\
\hline Glipizide & 147 & 100 & 130 & $71-86$ & 38 & 37 \\
\hline Extractable metabolites & 23 & 120 & 185 & $10-23$ & 46 & 53 \\
\hline Non extractable metabolites & 10 & 40 & 35 & $3-9$ & 16 & 10 \\
\hline
\end{tabular}

Table 4. Apparent "half-life" of glipizide and its metabolites (hours) between 6 and 12 h after i.v. or aral administration

\begin{tabular}{lllrr}
\hline & 3 controls i.v. & 3 controls p.o. & G.B. p.o. & F.G. p.o. \\
& GFR $>100$ & GFR $>100$ & GFR $=30$ & GFR $=10$ \\
\hline Total radioactivity & $2.3-4.8$ & $3.0-4.0$ & 6.0 & 12.0 \\
Glipizide & & $2.8-3.5$ & 4.5 & 4.4 \\
Extractable metabolites & & $2.6-6.0$ & $>20.0$ & $>20$ \\
Non extractable metabolites & & $2.0-4.3$ & $>20.0$ & $>20$ \\
\hline
\end{tabular}


normal kidneys (3 per os and 2 i.v.) had a comparable pattern (Fig. 5) whereas M. A. had a rather delayed excretion.

\section{Faecal Excretion}

The faecal excretion was irregular; the amount of radioactivity found in the 4 days faeces ranged from 3.5 to $18.2 \%$ of the administered dose.

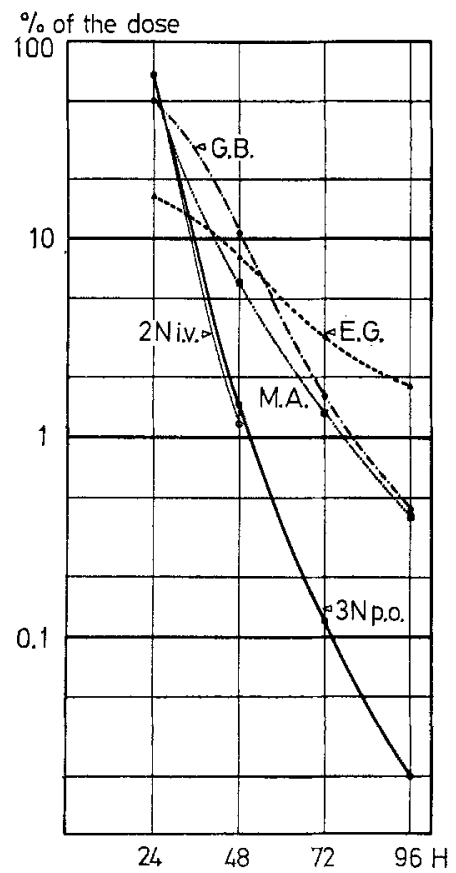

Fig. 5. Urinary excretion (per $24 \mathrm{~h}$ periods) of total radioactivity in percent of the given dose. Mean of 2 control subjects (N) after intravenous administration $(\mathrm{O}-\mathrm{O})$, mean of 3 controls (N) after oral administration (-) subject M.A. with normal kidney functions $(\ldots .$.$) ,$ patient G.B. with $\mathrm{GFR}=30 \mathrm{ml} / \mathrm{min}(-\cdot-\cdot-)$ and patient E. G. with GFR $=10 \mathrm{ml} / \mathrm{min}(\ldots)$

\section{Hypoglycaemic Effect after Oral Administration}

In the two subjects with rapid gastrointestinal absorption of glipizide (J.H. and Cl.B.), the lowest glucose levels and the maximal IRT responses were reached between 60 and $90 \mathrm{~min}$ after the ingestion of the drug, slightly before the maximal plasma concentration of radioactivity. The decrease of the glycaemia amounted to $54 \%$ and $63 \%$ respectively of the basal value. In the two subjects with delayed absorption, the glucagon injection interfered with the measurement of these parameters, and no conclusion can be drawn. Table 2 shows the glucose and IRI levels before the administration of the drug (time 0 ) and at the time of their maximal changes.

The injection of glucagon accelerated the rise of the blood sugar. Its effects on IRI levels, as well as the growth hormone patterns will be discussed elsewere [16].

\section{Subjects with Impaired Renal Function}

Plasma Levels of Glipizide and Its Metabolites

The maximal plasma levels are not different from the values found in the control group (Fig. 6) but the disappearance rate of the total radioactivity from the plasma is clearly reduced. An apparent "half-life" be-

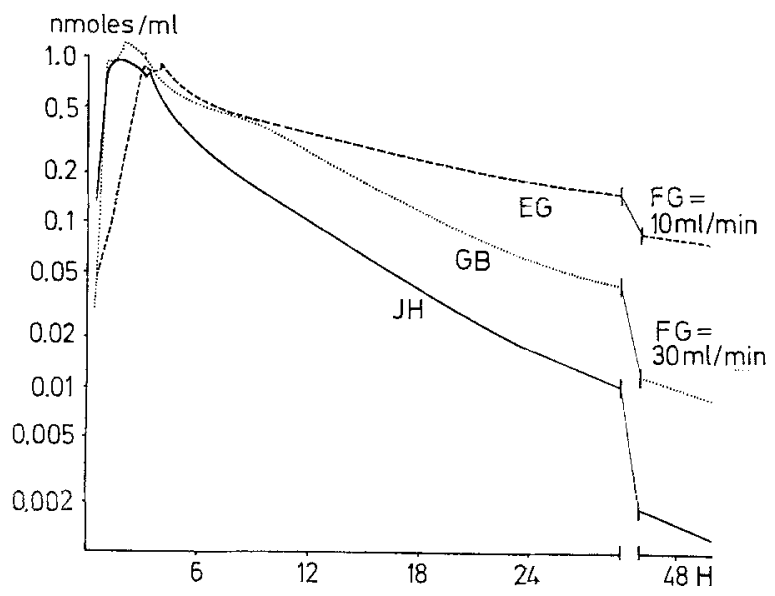

Fig. 6. Plasma concentrations of total radioactivity (expressed as nmoles $/ \mathrm{ml}$ ) in 2 patients with renal insufficiency (E.G. and G.B., FG $=$ GFR $=10$ and $30 \mathrm{ml} / \mathrm{min}$ ) following oral administration of a tablet, containing $5 \mathrm{mg}$ of ${ }^{14} \mathrm{C}$-glipizide. Comparison with 1 control subject (J.H.)

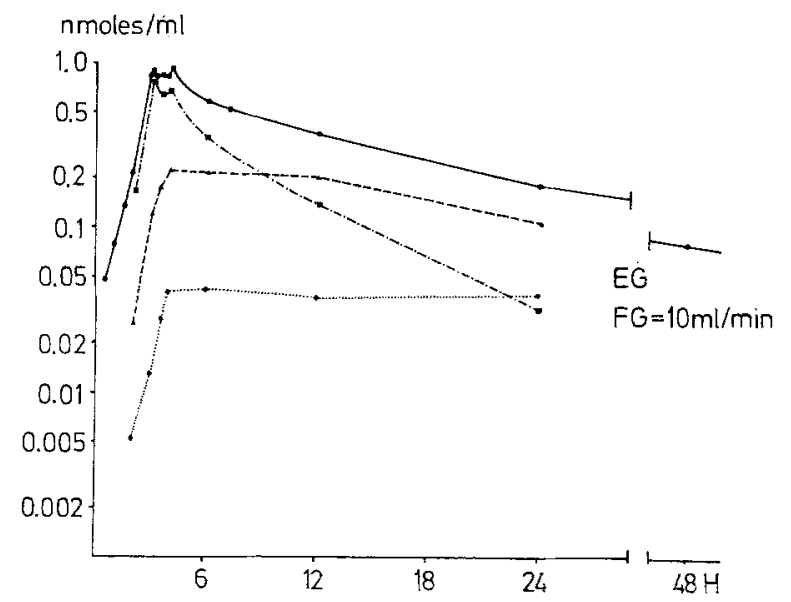

Fig. 7. Plasma concentrations of glipizide and its meta. bolites (expressed in nmoles per $\mathrm{ml}$ ) in one patient with renal insufficiency $(F G=G F R=10 \mathrm{ml} / \mathrm{min})$ following oral administration of a tablet, containing $5 \mathrm{mg}$ of ${ }^{14} \mathrm{C}$-glipizide. Total radioactivity ( - ), extractable glipizide $(\cdot-\cdot-\cdot \cdot)$, extractable metabolites (-...), unextractable metabolites $(\cdots \cdots \cdot)$

tween 6 and $12 \mathrm{~h}$ can be estimated to be $6 \mathrm{~h}$ for G. B. $(G F R=30 \mathrm{ml} / \mathrm{min})$ and $12 \mathrm{~h}$ for E. G. (GFR $=10 \mathrm{ml} /$ min) as compared to the $3.7 \mathrm{~h}$ found for the control group at the same times.

Fig. 7 shows that the disappearance rate of glipizide itself is not significantly reduced compared with normal subjects, but that the prolonged, apparent "half- 
life" is due to the accumulation in the plasma of the metabolites of the sulphonylurea. As a result the proportion of glipizide and of its derivatives in plasma at $12 \mathrm{~h}$ is considerably altered in patients with renal insufficiency, compared with normal subjects (Table 3). The levels of radioactivity in the plasma of G.B. and E.G. at $48 \mathrm{~h}$ are clearly increased since 0.01 and $0.08 \mathrm{nmoles} / \mathrm{ml}$ respectively were found as compared to $0.002 \mathrm{nmoles} / \mathrm{ml}$ on the average for the 4 controls.
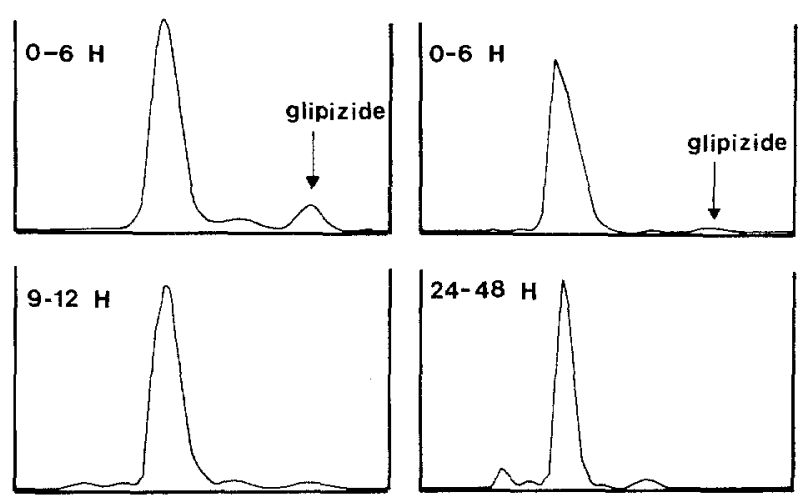

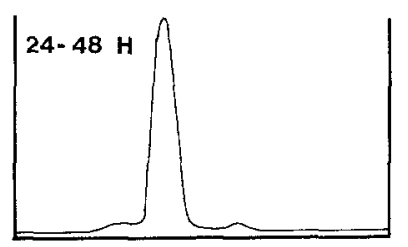

a) J.H.

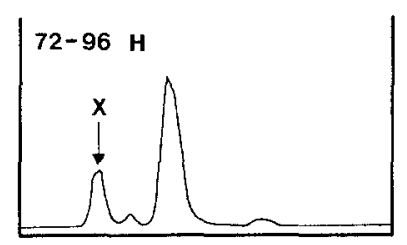

b) F.G.
Fig. 8. Paper chromatography of methylene chloride extracts of urines from 1 control subject (J.H. a) and one patient with renal insufficiency (E.G. b). In abscissa, from left to right: migration distance. In ordinate: arbitrarily chosen units

Table 4 gives a summary of all our data concerning the estimated "half-life" of glipizide and its metabolites between 6 and $12 \mathrm{~h}$ after the administration of the drug.

\section{Excretion of the Radioactivity}

Two situations can be distinguished: patient G.B. (GFR $=30 \mathrm{ml} / \mathrm{min}$ ) excreted after 4 days a quantity of radioactivity which was not different from the values found in control subjects (Tables 1 and 2); however E.G. $(G F R=10 \mathrm{ml} / \mathrm{min})$ showed a significantly reduced urinary excretion since, after 4 days, only $29.2 \%$ of the administered radioactivity was found in the urine.

The graphical representation of the radioactivity excreted per $24 \mathrm{~h}$ periods shows that the two patients with renal insufficiency had a delayed excretion (Fig. 5).

The faecal excretion was 19.1 and $12.2 \%$ of the radioactivity administered to G.B. and E.G. respectively.

\section{Hypoglycaemic Effect}

In the two patients with renal insufficiency the hypoglycaemic response was of the same order of magnitude as in normal subjects (the decrease in blood sugar was $50 \%$ and $56 \%$ of the basal values). The plasma IRI levels tended to be higher than in subjects with normal kidney functions (Table 2). In patient E.G. (GFR $=10 \mathrm{ml} / \mathrm{min}$ ) the glucose was still falling and IRI levels were still high $180 \mathrm{~min}$ after the administration of glipizide. At $150 \mathrm{~min}$ slight clinical symptoms of hypoglycaemia appeared, but disappeared quickly after the glucagon injection.

\section{Metabolites in the Urine}

The distribution of metabolites in the urine was comparable in all the subjects and was independent of both the route of administration and the presence of renal insufficiency.

The extraction of the urine with methylene chloride allows the separation of lipophilic-extractable metabolites and hydrophilic-unextractable metabolites. The proportion of unextractable metabolites was about $15 \%$ in the first urine $(0-6 \mathrm{~h})$ and increased with time; it represented $20 \%$ from 6 to $12 \mathrm{~h}, 30 \%$ from 12 to $24 \mathrm{~h}$ and approximatively $40 \%$ from 24 to $48 \mathrm{~h}$. In the urine from subjects with normal kidney functions the level of radioactivity in the urine was too low to allow this separation in the later specimens. In the patients with renal insufficiency, whose urinary pattern of radioactivity behaved identically up to this time, the proportion of unextractable metabolites was still rising after $48 \mathrm{~h}$ and reached $75 \%$ of the total radioactivity in the last samples $(72-96 \mathrm{~h})$.

Subject M.A. (normal kidney functions) was the only exception since the proportion of unextractable radioactivity reached a plateau at $35 \%$ after $48 \mathrm{~h}$. Because of the delayed excretion, this value was measurable up to the last urinary sample.

Chromatography of the extractable radioactivity allows the distinction between glipizide and its unconjugated metabolites. Fig. 8 a represents the paper chromatograms obtained with urine of patient J.H. They are representative for all the subjects studied with some differences which will be discussed below.

The main peak represents metabolites having the same Rf as the hydroxylated derivatives of glipizide. The amount of unchanged glipizide is small and is significant only in the first urines. For J.H. it represents $15 \%$ of the extractable radioactivity from 0 to $6 \mathrm{~h}$. The range for all the subjects after oral administration was 3 to $15 \%$ for the early urine. After intravenous administration this proportion is increased to about $30 \%$, but glipizide becomes undetectable in the later collections.

The patients with renal insufficiency showed the same pattern of extractable radioactivity as the subjects with normal kidney functions. The only difference 
was the presence in the late urine of patient E.G. (GFR $=10 \mathrm{ml} / \mathrm{min}$ ) of an unidentified metabolite (Fig. 8 b) which was found in the urine of no other subject.

\section{Discussion}

\section{Gastrointestinal Absorption}

The amount of absorbed glipizide was estimated on the basis of the urinary excretion of radioactivity following oral or intravenous administration. As shown in table 1 the results obtained after oral and intravenous administration were identical, and thus it was concluded that the gastrointestinal resorption of glipizide is almost complete. However, the finding that urinary excretion of radioactivity following oral administration is similar to that following intravenous administration, is not an absolute proof of complete gastrointestinal absorption. As a matter of fact, an orally administered drug can be metabolized by a different pathway than the same drug given intravenously: metabolites could be formed after oral administration, which are more readily excreted via the urine than those formed after intravenous administration. However, in the case of glipizide, the identity of the urinary excretion patterns of metabolites supports the hypothesis that the absorption of the drug is almost complete.

Because of the multiphasic pattern of elimination of the drug and its metabolites from the plasma the present data do not allow a satisfactory calculation of the kinetic parameters. We have thus avoided the calculation of an absorption half-life for glipizide.

The time at which maximal plasma levels occurred in subjects J.H. and Cl.B. (90 and $120 \mathrm{~min}$ ) are in full agreement with the values published by Ambrogi et al. [3]. The delayed absorption observed with F.Z. and M.A. is unexplained but is not exceptional since Anderson et al. [17] have observed maximal plasma levels of glibenclamide occurring between 90 and 360 min.

\section{Glipizide Concentration in Plasma}

The results of the present study do not allow a simple assignment of half-life elimination of glipizide from the plasma. Nevertheless it would seem that when the absorption and distribution phase of the drug is completed, it is eliminated for several hours with a halflife of about $4 \mathrm{~h}$. This figure differs from the half-life reported by Ambrogi et al. [3] for two human subjects (1.71 and $2.1 \mathrm{~h}$ ). The difference could easily be explained by the fact that a "single open compartment" mathematical treatment was applied to their data, whereas we arbitrarily calculated the "half-life" between 6 and $12 \mathrm{~h}$. As Gibaldi [18] has shown, a significant underestimate of half-life may be obtained if two-compartment kinetics are treated as single-compartment kine- tics, or if a three-compartment model system is interpreted in terms of the two-compartment model.

The radioactivity remaining in the plasma after $24 \mathrm{~h}$ is about $2 \%$ of the maximal plasma levels and this low value renders improbable an accumulation of the drug in the blood of subjects with normal kidney function, if they are given 2.5 to $15 \mathrm{mg}$ glipizide per day.

An apparent volume of distribution was calculated as follows: the total amount of drug administered intravenously $(1 \mathrm{mg})$ is divided by a theoretical initial blood concentration obtained by plotting the logarithms of the blood levels obtained at various times and extrapolating the second phase to zero time. We found the volume of distribution to be $20.4 \mathrm{l}$. However, it has been reported by Gibaldi [18] that this method of calculation overestimates this volume.

\section{Metabolism and Excretion}

The distribution of glipizide and its metabolites in the plasma and the urine is an indication that the drug is rapidly metabolised and that the metabolites are immediately excreted through the kidneys. The fact that the disappearance rate in plasma of glipizide was similar in normal subjects and in patients with renal insufficiency tends to confirm both this interpretation and the hypothesis that the kidney plays a minor role in the elimination from plasma of the drug itself. This hypothesis is in agreement with some of the conclusions of Ambrogi et al. [3]. Moreover the great chemical similarity of glipizide and glibenclamide suggests that glipizide is chiefly metabolised in the liver [15].

The high level of protein binding, as well as the good lipo-solubility of the sulphonylurea and the normally associated non-ionic diffusion of such substances from the tubular urine back into the blood, can explain the high levels of intact glipizide in the plasma and its almost complete absence in the urine. The more polar and hydrophilic metabolites are not reabsorbed by the proximal tubules and pass into the urine [19].

On the other hand, the presence in the latest urine samples of patient E. G. of an unusual metabolite is of interest. An analogous phenomenon has been described for acetohexamide $[6]$. This finding suggests that either an unknown metabolic pathway has evolved in order to clear the blood of substances which cannot be handled by the kidneys, or that this represents a normal transformation of glipizide, which cannot be visualized under normal conditions.

From the present observations a general trend in the metabolism of glipizide can tentatively be proposed. The liver metabolises the sulphonylurea mainly into hydroxylated and conjugated derivatives as suggested by both the disappearance rates and the similar metabolite patterns in blood and urine of the normal subjects and the uraemic patients during the first hours after the administration. The metabolites are preferentially excreted by the kidneys and unchanged 
glipizide appears in the urine only when its plasma levels are high. When the plasma concentration of glipizide becomes low the main part of the drug has become hydroxylated and these metabolites are then also conjugated, as suggested by the decreasing proportion of extractable metabolites in the later urine.

The influence of renal insufficiency is, as can easily be understood, not so much on the metabolism of the drug itself, but on the clearance of its metabolites, which subsequently accumulate in the blood. The hydroxylated metabolites of glipizide, which represent the most important part of the radioactivity found in the urine have probably no hypoglycaemic effect [20], and $\mathrm{N}$-acetamide-(ethyl-benzene-sulfonyl) N'-cyclohexylurea, which seems to account only for $1 \%$ of the radioactivity found in human urine [3], has a potency ratio to glipizide of 1 to 20. Therefore, it seems unlikely that the longer hypoglycaemia observed with the patient in severe renal insufficiency (E.G.) was due to the accumulation of the metabolites. As discussed by Petitpierre et al. [7], renal insufficiency constitutes an important predisposition to hypoglycaemic incidents in diabetics treated with sulphonylureas, but blood levels of the drug or its metabolites seem not to be the unique cause of such prolonged hypoglycaemia. This problem will be discussed in details elsewere [16].

In conclusion our data show that glipizide is an exceptionally well absorbed sulphonylurea and that it has a very potent hypoglycaemic effect. The pharmacokinetic properties of this drug render it suitable for oral therapy in maturity-onset diabetes mellitus.

Acknowledgements. We wish to express our gratitude to Dr. A. Monro and his team for their continuous help during this work, as well as Dr. G. Valzelli and Mr. G. Goldaniga for their advice. We are grateful to Dr. B. Kaye for the determination of the radioactivity in all the faecal samples, as well as to Mrs. Marcel Chauffat and Miss Jacqueline Spahr for their skilled technical assistance. Finally we wish to thank Pfizer Europe for the gift of the ${ }^{14} \mathrm{C}$-labelled glipizide.

\section{References}

1. Ambrogi, V., Bloch, K., Daturi, S., Griggi, P., Logemann, W., Mandeli, V., Parenti, M.A., Rabini, T., Usardi, M.M., Tommasini, R.: Pharmacological study on a new antidiabetic: $\mathrm{N}$-\{4-[ $\beta$-(5-methyl-pyrazine-2carboxamido)-ethyl]-benzene-sulfonyl $\}-N^{\prime}$-cyclohexyl urea or K 4024. Arzneimittel-Forsch. 21, 208-215 (1971)

2. Pedrazzi, F., Pisani Ceretti, A., Losi, S., Bommartini, F., Artini, D., Emanueli, A.: Evaluation in hospitalized subjects of a new hypoglycemic sulfonylurea, glydiazinamide. Arzneimittel-Forsch. 21, 220-225 (19.71)

3. Ambrogi, V., Artini, D., Fucella, L. M., Goldaniga, G., Orsini, G., Ronchi, R., Tamassia, V., Valzelli, G., Angelucci, R.: Farmacocinetica e metabolismo in animali da esperimento e nell'uomo della $\mathrm{N}-\{4-[\beta-(5-$ metilpirazina-2-corbossiamido)-etil]-benzensulfonil\}$\mathrm{N}^{\prime}$ cicloesil-urea (K 4024). Boll. chim. farm. 111, 251 264 (1972)

4. Stowers, J.M., Constable, L.W., Hunter, R.B.: A clinical and pharmacological comparison of chlorpropamide and other sulfonylureas. Ann. N. Y. Acad. Sci. $74,689-695(1959)$

5. Ueda, H., Sakurai, T., Ota, M., Nakajima, A., Kamii, K., Maezawa, H.: Disappearance rate of tolbutamide in normal subjects and in diabetes mellitus, liver cirrhosis and renal disease. Diabetes 12, 414 -419 (1863)

6. Cohen, B.D., Galloway, J.A., McMahon, R.E., Root, M.A., Henriques, K.J.: Carbohydrate metabolism in uremia : blood glucose response to sulfonylurea. Amer. J. med. Sci. 254, 608-618 (1967)

7. Petitpierre, B., Fabre, J.: Effet de l'insuffisance rénale sur l'action hypoglycémiante des sulfonylurées. Schweiz. med. Wschr. 102, 570-578 (1972)

8. Dubach, U.C., Bückert, A., Forgo, I., Rentsch, G.: Etude pharmaco-clinique du glibornuride. Symposium international sur les agents hypoglycémiants. Evian 1971

9. Zender, R.: Une microméthode automatique pour l'analyse quantitative des aldohexoses dans les liquides biologiques par l'o-toluidine. Clin. chim. Acta $8,351-358$ (1963)

10. Hales, C.N., Randle, P.Y.: Immunoassay of insulin with insulin-antibody precipitate. Biochem. J. 88, $137-146$ (1963)

11. Catt, K., Tregear, G.W.: Solid-phase radioimmunoassay in antibody-coated tubes. Science 158, 15701572, (1967)

12. Hodges, P.: Personal communication

13. Valzelli, G.: Personal communication

14. Bray, G.A.: A simple efficient liquid scintillatos for counting aqueous solutions in a liquid scintill. ion counter. Analyt. Biochem. 1, 279-285 (1960)

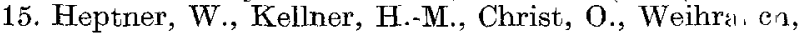
D.: Metabolismus von HB 419 am Tier. Arzneimu i $\in$ lForsch. 19, 1400-1404 (1969)

16. Zahnd, G., Balant, L., Fabre, J.: In preparation

17. Anderson, J., Stephenson, R.J., Tomlinson, R.W s., Weinberg, A.L.: Studies with ${ }^{14} \mathrm{C}$-labelled ylib $\mathrm{n}$ clamide. Postgrad. med. J. Dec. Suppl. 42-45 (19 0$)$

18. Gibaldi, M.: Pharmacokinetic aspects of drug met $b$. olism. Ann. N.Y. Acad. Sci. 179, 19-31 (1971)

19. Rupp, W., Christ, O., Heptner, W.: Resorption, A i. scheidung and Metabolismus nach intravenöser uird oraler Gabe von HB 419 an Menschen. Arzneimitt 'Forsch. 19, 1428-1434 (1969)

20. Carlo Erba: Personal communication

Prof. J. Fabre

Policlinique Universitaire de Médecine

Rue Micheli-du-Crest, 24

Genève

Switzerland 